\title{
NOTAS METODOLÓGICAS DE UMA PESQUISA SOBRE AS POLÍTICAS PÚBLICAS DE ESPORTE ${ }^{1}$
}

\author{
Renata Maria Toledo ${ }^{2}$ \\ Maria Tarcisa Silva Bega
}

\section{Resumo}

Este trabalho visa a expor a estrutura teórico-metodológica que confere sustentação a uma pesquisa de doutoramento em sociologia, ainda em curso, que tem por enfoque as políticas públicas setoriais de esporte que se desenvolveram ao longo das gestões de Jaime Lerner (1995-2002) e Roberto Requião (2003-2010). Dividido em duas partes, o texto apresenta, na primeira seção, o processo de construção do objeto de pesquisa, identificando os pontos de inflexão que sofreu desde o projeto original até a formatação final da problematização sobre a qual nos debruçamos em nosso estudo. Em seguida, efetua-se uma explanação sobre a estrutura metodológica, o quadro de informações utilizadas, bem como as respectivas fontes para levantamento dos dados que se fizeram necessárias para a análise do referido objeto.

Palavras-chave: Metodologia, políticas públicas, esporte, direito social, sociologia.

\begin{abstract}
This paper exposes the theoretical and methodological framework of an ongoing doctorate research in Sociology, which focuses on the sport policies developed along Jaime Lerner's (1995-2002) and Roberto Requião's (2003-2010) terms. It is a twofold work. Firstly, it presents the development of the research object, identifying the primarily changes that shift its original to its final design. Then, it indicates its methodological framework, the information required and the sources used to collect data that were necessary for the analysis of the research object.
\end{abstract}

Key words: methodology, public policy, sport, social right, sociology

\section{Resumen}

Este trabajo busca exponer la estructura teórica- metodológica que da sustento a una investigación de doctorado en sociología, que está en curso. Tiene como enfoque las políticas sectoriales de deporte que se desarrollaron durante la gestión de Jaime Lerner (1995-2002) y Roberto Requião (2003-2010). El texto está dividido en dos partes, en su primera parte presenta el proceso de construcción del objeto de investigación, identificando los puntos de inflexión que sufrió desde el proyecto original, hasta la formulación final de la problematización sobre la cual trabajamos a través de nuestro estudio. Posteriormente, se efectúa una explicación sobre la estructura metodológica, la información utilizada y las fuentes de los datos levantados que se requirieron para el análisis de dicho objeto.

Palabras llaves: Metodología, políticas públicas, deporte, derecho social, sociología

\section{INTRODUÇÃO}

O presente trabalho tem por finalidade apresentar os fundamentos teóricos metodológicos que direcionam a elaboração de uma pesquisa, ainda em curso, que se desenvolve no interior do Programa de Pós-Graduação em Sociologia da Universidade

\footnotetext{
${ }^{1}$ DOI deste artigo: http://dx.doi.org/10.5380/recp.v5i2.37496

2 Doutoranda em Sociologia na Universidade Federal do Paraná. Bolsista do Programa de Reestruturação Expansão das Universidades Federais (REUNI)

3 Professora Associada I da Universidade Federal do Paraná; atua no Programa de Pós-Graduação em Sociologia, nas linhas de pesquisa Cultura e Sociabilidades e Instituições e Poder.
} 
Federal do Paraná (UFPR). Trata-se de uma tese de doutorado desenvolvida na linha de pesquisa Instituições e Poder, que recepciona trabalhos que focalizam a história e a sociologia política e possui, como uma de suas áreas temáticas, a análise comparada de políticas públicas. A pesquisa em questão versa sobre as políticas públicas setoriais de esporte, estabelecendo uma análise comparada entre os governos estaduais de Jaime Lerner (19952002) e Roberto Requião (2003-2010), com vistas a identificar em que medida sua formatação coaduna com a alegação, presente nos discursos político e acadêmico, de que o esporte é um direito "social".

Nosso objetivo não se resume a estabelecer um relato dos elementos que compõem a sua estrutura metodológica, mas, também, apontar alguns pontos de inflexão que fizeram com que o trabalho tomasse os rumos que tomou, dentre inúmeros outros possíveis. Isso porque entendemos que o desenvolvimento da pesquisa em muito se assemelha ao processo de criação artística, tal como descrito por Mannheim (1974), em seu ensaio sobre a sociologia do conhecimento. Afirma o autor que nem o referido processo nem o produto que dele resulta podem ser analisados a partir da premissa de que o artista enxerga antecipadamente o molde e o formato finais de seu trabalho e, simplesmente, os reproduz a posteriori. Ao contrário, tanto a obra quanto a própria ideia que orienta sua conformação se desenvolvem ao longo de sua construção e, sendo assim, "todo 'fator real', toda linha já desenhada, todo movimento da mão, não somente determinam aqueles que lhe seguirão, mas também criam novas possibilidades não-sonhadas de antemão" (MANNHEIM, 1974, p.45).

Parece-nos, pois, não haver dúvidas que tais considerações refletem significativamente o processo de produção acadêmico-científica, de modo que entre o projeto de pesquisa original e o seu relatório final há um sem-número de modificações que, muitas vezes, afasta por completo o segundo do primeiro. Muitas dessas alterações são resultantes da participação em atividades acadêmicas, tais como o acompanhamento de disciplinas obrigatórias ou optativas, seminários, congressos, grupos de estudos, orientação, dentre outros. Outras provêm da experiência da pesquisa de campo, quando a "realidade" pesquisada é confrontada. Outras, ainda, são oriundas de eventos, pessoais ou profissionais, que, mesmo não apresentando relação direta com a pesquisa, podem municiar o pesquisador com novos esquemas de percepção e interpretação, que podem ser aplicados em sua investigação. 
Nossa perspectiva, aqui, não é recuperar detalhadamente as experiências que se deram durante o curso de doutorado, influenciando, em maior ou menor grau, a elaboração da pesquisa. Ao longo deste artigo, buscamos apenas enfatizar as alterações que foram decisivas para seu desenho definitivo, as premissas epistemológicas que as acompanharam e os respectivos desdobramentos operacionais. Para tanto, dividimos o texto em duas seções. $\mathrm{Na}$ primeira delas, situamos a área temática da pesquisa e discorremos sobre a construção do objeto da pesquisa. Em seguida, discorremos sobre sua estrutura metodológica, indicando os fundamentos teóricos que lhe dão sustentação bem como o quadro de informações que se fizeram necessárias na efetivação de nossa análise.

\section{DE PRESSUPOSTO AO CENTRO DO PROBLEMA: A CONSTRUÇÃO DO OBJETO DE PESQUISA}

O interesse pelas políticas públicas, particularmente aquelas voltadas para os setores educacional e esportivo, surgiu de experiências a que tivemos acesso ao longo do curso de Licenciatura em Educação Física da Universidade Federal do Paraná, entre os anos de 2002 e 2005. Com ele, despontou também o flerte com as Ciências Sociais que, contudo, só adquiriu uma dimensão acadêmica quando da admissão no Programa de Pós-Graduação em Sociologia da mesma universidade, alguns anos mais tarde. O projeto de pesquisa que então apresentamos trazia a marca da formação básica, sendo permeado por um conjunto de dilemas e questões característicos de seu universo. Dentre as mais significativas, estava a percepção de que a ação estatal direcionada ao fomento do esporte de alto rendimento colidia com o direito social ao esporte, instituído pela Constituição Federal de 1988, mas, flagrantemente, desrespeitado pelos governos que sucederam à sua promulgação.

O óbice à sua efetivação residia, em nosso entendimento, em duas razões principais: a) a consolidação histórica de um modelo seletivo de política esportiva, que empenhava os recursos físicos e financeiros do Estado brasileiro na atividade esportiva de alta performance, vinculada às organizações esportivas integrantes do sistema esportivo internacional, a exemplo do Comitê Olímpico Brasileiro (BRACHT, 2003; VERONEZ, 2005); b) a orientação neoliberal subjacente às políticas públicas formuladas no período que se seguiu à promulgação do texto constitucional. Partindo desse entendimento, nossa proposta inicial de pesquisa tinha como objetivo geral investigar, comparativamente, as políticas públicas de esporte e lazer no estado do Paraná, durante as gestões de Jaime Lerner e Roberto Requião, a fim de identificar em que medida elas se aproximavam desse 
modelo seletivo consolidado historicamente e fortalecido pela concepção neoliberal de gestão das políticas sociais.

É possível dizer que, acompanhando as premissas predominantes em uma parcela significativa da produção acadêmica sobre o tema, levada a efeito na área da Educação Física, o projeto de pesquisa encontrava-se balizado em três pressupostos epistemológicos centrais: a) a noção de que o direito "social" ao esporte foi criado a partir da Constituição Federal de 1988; b) a perspectiva de que as manifestações esportivas na atualidade podem ser classificadas em esporte educacional, esporte-participação e esporte de alto rendimento, tal como a tipologia jurídica estabelecida pela lei $\mathrm{n}^{\circ}$ 9.615, de 24 de março de 1998, que regulamenta o esporte no país; c) o entendimento de que, em virtude de sua interface com o lazer, o esporte-participação é a manifestação esportiva através da qual o direito "social” ao esporte pode se realizar, haja vista o disposto nos artigos $6^{\circ}$ e 217 do texto constitucional ${ }^{4}$.

As primeiras alterações da proposta original de pesquisa foram resultantes da participação nas seguintes disciplinas do curso de pós-graduação em Sociologia: a) Métodos e Técnicas de Pesquisa; b) Método em Ciência Política; c) Seminários Metodológicos. Dentre estas, duas foram mais decisivas para o estágio em que a pesquisa se encontrava. Primeiramente, o redimensionamento do objeto, com a retirada do lazer do foco de análise da pesquisa. Ainda que, usualmente, a produção acadêmica se refira, em seus escritos, às “políticas públicas setoriais de esporte e lazer" (STAREPRAVO, 2011), entendemos, a partir da discussão sobre os projetos de pesquisa levada a efeito nas três disciplinas, que o foco de nosso estudo estava nas políticas de esporte. Como evidência dessa constatação, estava o fato de que no projeto original não constatava qualquer referência ao lazer, além da própria expressão indicada acima. Sendo assim, optamos por tratar o lazer apenas como elemento subsidiário, na medida em que a análise das políticas de esporte assim o exigisse. A segunda alteração, que poderíamos dizer significativa para a pesquisa, resultou da incorporação da dimensão cultural à análise das políticas de esporte, antes voltada para a estrutura legal e organizacional da ação do Estado para o setor. Tratou-se, aqui, de levar em conta, na construção do objeto de pesquisa, a sua condição de símbolo nacional (HOBSBAWN, 1988; HARGREAVES, 1992; HOULIHAN, 1997).

\footnotetext{
${ }^{4} \mathrm{O}$ artigo $6^{\circ}$ da Constituição Federal estabelece que "são direitos sociais a educação, a saúde, a alimentação, o trabalho, a moradia, o lažer, a segurança, a previdência social, a proteção à maternidade e à infância, a assistência aos desamparados, na forma desta Constituição" (BRASIL, 2011, p.20). Por sua vez, o artigo 217, que dispõe sobre as práticas esportivas, estabelece, em seu $\ 3^{\circ}$, que "o Poder Público incentivará o laz̧er, como forma de promoção social' (BRASIL, 2011, p.140, grifo nosso).
} 
Outro conjunto de alterações incorporadas no processo de construção do objeto da pesquisa proveio da apropriação e aprofundamento de alguns elementos teóricos correlatos à área temática em que desenvolvemos nosso estudo. Três noções foram aqui fundamentais para redirecionar a análise para um caminho não planejado de início: o conceito de "direito social" estabelecido por Marshall (1967), em suas reflexões sobre a cidadania social; as proposições teórico-metodológicas do estudo de Esping-Andersen (1991) sobre o Welfare State; e, finalmente, a concepção teórico-metodológica de Max Weber (2001b) sobre a abordagem do direito pela sociologia. Parece-nos relevante recuperar, brevemente, essas três noções, com vistas a explicitar o modo como cada uma delas contribuiu para a redefinição do objeto de nossa pesquisa.

O sociólogo inglês Thomas Marshall abordou a questão dos direitos sociais em uma conferência realizada em 1950. De acordo com suas proposições, os direitos sociais são, ao lado dos direitos civis e dos direitos políticos, elementos integrantes da cidadania social. Compreendem a extensão, a todos os indivíduos que integram uma dada sociedade, do direito de participar da riqueza social. Erigindo-se em uma base territorial nacional, os direitos sociais se constituem quando são introduzidos na ordem jurídico-institucional do país. Sua garantia se dá, predominantemente, através da provisão e serviços pelo Estado, sendo que são as instituições vinculadas ao Poder Executivo aquelas que detêm o papel principal no cumprimento de tal garantia. No caso inglês, analisado por Marshall, esses direitos se desenvolveram, sobretudo, no século XX, quando já se encontravam consolidados os direitos civis e os direitos políticos.

Essa definição de Marshall nos levou a dois questionamentos. O primeiro deles residia no sentido do "direito de participar da riqueza social". Foi em Esping-Andersen (1991) que encontramos subsídios para estabelecer uma compreensão a respeito, na medida em que este autor propõe que o advento dos direitos sociais possibilitou uma ruptura da vinculação incondicional do acesso a bens e serviços relativos ao bem-estar social à performance do indivíduo no mercado, fenômeno a que denominou desmercadorização (ESPING-ANDERSEN, 1991). A segunda questão dizia respeito à necessidade de se identificar o conteúdo substantivo desta "riqueza social". Marshall pondera que não existe um parâmetro universal que possa determinar a sua substância, sendo que cada sociedade que dispõe do estatuto da cidadania social cria os seus próprios princípios para definir os elementos que a compõem.

Em virtude do seu caráter "desmercadorizante", os direitos sociais desempenharam um relevante papel na conformação do Welfare State, modelo estatal em que as diretrizes 
liberais que preconizavam ser o mercado o mediador exclusivo das relações sociais foram suplantadas. Contudo, Esping-Andersen sustenta não ser possível compreender o processo de seu desenvolvimento se o analisarmos apenas em termos de "direitos e garantias". O autor defende ser necessário, sobretudo, estabelecer uma inter-relação destes com os papeis desempenhados pelo Estado, pelo mercado e pela família na provisão de bens e serviços a eles relativos, considerando que "não é a mera presença de um direito social, mas as regras e pré-condições correspondentes, que dita a extensão em que os programas de bem-estar social oferecem alternativas genuínas à dependência em relação ao mercado" (ESPINGANDERSEN 1991, p.103). Isso porque, através da análise de quatro variáveis - a) articulação entre as ações do Estado, do mercado e da família; b) a elegibilidade dos benefícios correspondentes aos direitos sociais; c) o alcance das políticas sociais; d) as especificidades políticas do país -, Esping-Andersen identificou diferentes regimes de Welfare State que resultam em níveis distintos de desmercadorização para aquisição de bens e serviços de bem-estar, ainda que estes estejam consagrados na legislação nacional como direitos sociais.

As formulações teóricas de Marshall e Esping-Andersen são respaldadas por uma leitura do direito social como um fenômeno social e histórico, e não como uma categoria jurídica abstrata. Esse se tornou um ponto de inflexão para a construção do objeto de nossa pesquisa, quando nos apropriamos da concepção weberiana sobre a análise sociológica do direito. Max Weber (2001b) propõe a existência de uma distinção entre a ciência jurídica e a sociologia quando se trata da abordagem das normas jurídicas, assinalando que, se a primeira tende a se preocupar com o seu conteúdo objetivo, à segunda interessam, substancialmente, as condições sociais e históricas que conduziram à sua produção bem como os eventuais efeitos que, uma vez instituídas, produzem nas relações sociais. Em outros termos, a análise sociológica não se limita à verificação da existência e (des)cumprimento das regras e dispositivos que integram o aparato legislativo, mas

1) leva em consideração também a probabilidade de divulgação de tais ideias [contidas nos enunciados legais], e 2) faz uma reflexão no sentido de que, em determinadas circunstâncias bem precisas, o fato de predominar na cabeça de determinados homens certas idéias, fato que pode ser constatado empiricamente, certas idéias que dizem respeito ao "sentido" de um "preceito jurídico", considerado como sendo válido tem, por conseqüência, que o agir pode ser orientado racionalmente em certas "expectativas" e, portanto, proporciona a indivíduos concretos determinadas "possibilidades". Este fato pode ter grande influência sobre o seu comportamento. Nisto consiste o significado sociológico conceitual da "validade" empírica de um "preceito jurídico" (WEBER 2001b, p.323). 
Podemos considerar que o elemento nuclear desta argumentação de Max Weber encontra-se também no entendimento de que, a despeito de sua relevância como mecanismo diretivo da ação humana que produz resultados para a política em geral e para as políticas públicas, em particular, os dispositivos legais não são seu único eixo de orientação. Para além das regras formais, eles desempenham também um papel no processo de conformação das políticas públicas: "os sistemas de símbolos, os esquemas cognitivos e os modelos morais que fornecem 'padrões de significação' que guiam a ação humana" (HALL \& TAYLOR 2003, p.208). Essas reflexões nos conduziram ao entendimento de que, embora fosse um requisito necessário, a simples inclusão do esporte no texto constitucional de 1988, como "direito de cada um" e "dever do Estado" (BRASIL 2011), não era suficiente para atestarmos a existência de um direito "social" ao esporte, sendo preciso, também, identificar se a criação de tal dispositivo redundou em um processo de desmercadorização do acesso às práticas esportivas. Dito de outra maneira, o aspecto fundamental residia não em sua inclusão na Constituição Federal, mas nos (eventuais) efeitos que tal consagração no ordenamento jurídico produziram nas relações sociais. Quais relações? Aquelas que têm lugar no processo de formulação e execução das políticas públicas setoriais de esporte que se seguiram à promulgação do texto constitucional.

Em face do exposto até aqui, confrontamos as três premissas que balizaram a proposição original de nosso objeto de pesquisa. Ao invés do entendimento de que o direito social ao esporte foi criado pela Constituição Federal de 1988, passamos ao pressuposto de que a inclusão do esporte no texto constitucional como um "direito de cada um", no título que dispõe sobre a ordem social, não é suficiente para que empiricamente o esporte se apresente como um direito social, tanto no que se refere à sua incorporação nos processos de formulação e implementação das políticas públicas, quanto no que concerne à própria percepção social sobre tal relação. Fundamentando-nos na concepção weberiana sobre a abordagem do direito, suplantamos a segunda premissa a partir da refutação da tipologia estabelecida pela lei 9.615, de 24 de março de 1998, como um instrumental explicativo do fenômeno esportivo na atualidade. Ao invés disso, admitimos a possibilidade da existência de uma maior diversidade de manifestações esportivas na sociedade contemporânea, como indicam Marchi Jr \& Afonso (2007). Também consideramos a referida tipologia inadequada, porque, como indica Almeida (2010), não raro há uma indistinção entre as manifestações esportivas previstas em lei. Finalmente, refutamos a noção de que o esporte-participação é o parâmetro capaz de definir se as políticas públicas vêm garantindo a condição do esporte de direito social. 
Como consequência, procedemos a um reposicionamento do objeto de pesquisa, de forma que a identificação do esporte como um direito social passou da condição de pressuposto para o núcleo central de nossa problematização, que passou a enfocar a relação entre as políticas públicas e o direito "social" ao esporte, traduzindo-se na seguinte pergunta de pesquisa: em que medida as diretrizes das politicas públicas setoriais de esporte implementadas no estado do Paraná ao longo das gestões de Jaime Lerner (1995-2002) e de Roberto Requião (2003-2010) atuaram no sentido de garantir ao esporte a condição de um direito "social"? Não obstante, o recorte empírico permaneceu o mesmo. Nós o mantivemos, sobretudo, por duas razões: a) a baixa incidência de análises sobre as políticas de esporte na esfera estadual (SOUZA, 2003); b) as condições de execução (QUIVY \& CAMPENHOUDT, 1992) do cronograma da pesquisa, considerando o prazo e os recursos disponíveis para sua realização. A série histórica, delimitada entre 1995 e 2010, foi adotada em virtude do fato de serem as gestões estudadas posteriores à promulgação da Constituição Federal de 1988, posto que foi a partir de então que o esporte adquiriu o status legal de um direito. Além disso, levamos em conta que tanto Jaime Lerner quanto Roberto Requião foram contemplados com o instituto da reeleição, o que propiciou uma maior continuidade de suas respectivas políticas governamentais e, por conseguinte, a possibilidade de localização de uma gama maior de dados empíricos pertinentes ao problema investigado.

Essa reelaboração se deu sob novas premissas epistemológicas. Os fundamentos weberianos sobre a abordagem do direito pela sociologia resultaram na adoção de dois movimentos analíticos: a) a identificação da conjunção de fatores e interesses que permitiram que, em um dado contexto histórico, as leis definidoras do esporte como um direito tenham sido produzidas; b) a observação do tipo de efeito(s) que essas leis exerceram nas relações sociais que passaram a regular. Em termos operacionais, isso representou, primeiramente, $\mathrm{o}$ reconhecimento da Constituição Federal de 1988 e da legislação infraconstitucional como eventos históricos, resultantes de uma constelação de fatores políticos, econômicos, sociais e culturais.

Além disso, abordamos o direito social não como uma abstração jurídica, mas, como um fenômeno social e histórico. Sustentando-nos em Marshall (1967) e EspingAndersen (1991), assumimos a universalidade e a desmercadorização como suas características típico-ideais centrais. A primeira indica a pretensão de seu alcance, ou seja, quando um elemento qualquer da vida social é alçado à condição de um direito social, subjaz a perspectiva de torná-lo de igual acesso a todos os cidadãos. O que se busca, nesse caso, é 
uma igualdade de chegada, ou seja, de acesso, o que difere dos direitos econômicos, cuja premissa é uma igualdade de partida (DRAIBE 1990). A segunda, por seu turno, remete à ruptura do condicionamento ao desempenho do indivíduo no mercado como forma exclusiva de acesso aos bens e/ou serviços correspondentes aos direitos sociais (MARSHALL 1967; ESPING-ANDERSEN, 1991). Tomamos essas duas características como nosso novo parâmetro analítico e, consequentemente, destituímos o esporte de alto rendimento de tal condição.

Com vistas a responder à problematização proposta e estruturar nossa análise, delineamos uma hipótese de trabalho. Levando em consideração a discussão teórica até aqui apresentada, bem como a inclusão da dimensão cultural do esporte - de símbolo nacional - no conjunto de fatores que contribuem para definir as políticas públicas para o setor, delineamos a seguinte hipótese: a baixa institucionalidade do esporte como um direito "social", associada à sua significação cultural, cria elementos de tensão que fazem com as políticas de esporte se justifiquem por uma retórica de equidade, mas operem através de um parâmetro de acumulação, de modo que a tendência é de que essas políticas atuem de modo ainda incipiente para garantir ao esporte a condição de um direito desta natureza. Para tal formulação, tomamos por equidade "o ideal de reduzir ou extinguir desequilíbrios sociais e por acumulação as ações destinadas a aumentar a oferta de bens e serviços disponíveis" (SANTOS, 1987, p.13). Pressupomos, ainda, que a referida tendência se manifesta independente do espectro político que esteja na titularidade do governo, isto é, a despeito das diferenças político-ideológicas entre Jaime Lerner e Roberto Requião, o pressuposto é de que nas gestões de ambos as políticas públicas setoriais de esporte se articularam a partir de uma concepção semelhante, centrada num modelo que contraria a perspectiva de universalização do acesso à prática esportiva. Feitas essas considerações, encontramo-nos em condições de apresentar a estrutura metodológica delineada para responder à nossa problematização.

\section{DESDOBRAMENTOS OPERACIONAIS: A ESTRUTURA METODOLÓGICA DA PESQUISA}

A dinâmica do processo de construção da pesquisa resultou em uma nova delimitação do objeto de estudo, que passou a focalizar a relação entre as políticas públicas e o direito "social" ao esporte em uma esfera subnacional de governo. Essa nova delimitação resultou também em outras modificações, agora de natureza operacional, o que nos levou a evidenciar a interdependência entre os pressupostos epistemológicos adotados 
e a estrutura metodológica da pesquisa. O primeiro desdobramento operacional foi a demanda por um constructo sociológico da noção de direito social, tanto do ponto de vista da teoria quanto da empiria, com vista a compreender o modo como o esporte foi discursivamente incorporado em seu leque de abrangência em nossa sociedade.

E considerando que partimos de uma acepção que o entende também como um fenômeno histórico, o segundo desdobramento operacional residiu na identificação das particularidades de seu desenvolvimento no Brasil. Do ponto de vista da construção do objeto, isso significa que, ainda que nosso problema de pesquisa estivesse vinculado a fenômenos sociais de caráter mais geral, como o Estado, o esporte e o direito, seria necessário circunscrevê-lo em um quadro específico de relações sociais, o que implicava a reconstituição de sua articulação a partir do modo como se deu em nossa individualidade histórica. Cabe ressaltar que, para este segundo desdobramento convergiu também a proposição metodológica de Max Weber segundo a qual a reconstituição dos traços mais genéricos constitui-se como a etapa preliminar do processo de conhecimento dos fenômenos históricos, à qual se seguem outras três.

\begin{abstract}
A segunda operação, completamente nova e independente, apesar de se basear nessa tarefa preliminar, seria a análise e a exposição ordenada do agrupamento individual desses 'fatores' historicamente dados e da combinação concreta e significativa dele resultante. Mas acima de tudo consistiria em tornar inteligível a causa e a natureza deste significado. A terceira operação seria remontar o máximo possível ao passado e observar como se desenvolveram as diferentes características individuais dos agrupamentos de importância para o presente, e proporcionar uma explicação histórica a partir destas constelações anteriores, igualmente individuais. Por fim, uma quarta operação possível consistiria na avaliação das constelações possíveis no futuro (Weber, 2001a, p.127).
\end{abstract}

Essas formulações encontram suas raízes em um princípio epistemológico central na teoria weberiana, qual seja, na perspectiva de que o escopo da ciência social é estabelecer uma compreensão da realidade naquilo que ela tem de específico, de modo a contemplar, "por um lado, as conexões e a significação cultural das nossas diversas manifestações na sua configuração atual e, por outro, as causas pelas quais ela se desenvolveu historicamente de uma forma e não de outra" (WEBER, 2001a, p.124). Um mecanismo heurístico relevante para levar a efeito esta tarefa é a comparação, visto que ela permite situar os elementos característicos do universo particular pesquisado que também se apresentam em outros contextos, bem como reputar os traços que lhe são específicos e que, portanto, denotam a sua singularidade histórica (COHN, 2010).

Optamos, pois, por uma abordagem comparativa, com vistas a identificar as particularidades que os referidos fenômenos adquiriram em nossa individualidade histórica, 
mas também e, sobretudo, o fizemos para localizar a singularidade do direito "social" ao esporte em relação aos componentes do quadro de direitos sociais consolidado em nossa sociedade. Com efeito, a hipótese de trabalho que elaboramos para orientar esta pesquisa é composta por dois elementos: o desenho institucional das políticas públicas para o setor esportivo e a significação cultural do esporte moderno. $O$ potencial que julgamos elucidativo, no primeiro, se refere ao caráter pressuposto de baixa institucionalidade que o esporte possui em comparação a outros elementos, integrantes do quadro de direitos sociais tal como estes se conformaram no país. Sendo assim, o recurso da comparação foi utilizado para situar o direito ao esporte, em relação a um conjunto de direitos articulados social e juridicamente sob a rubrica de "sociais", selecionados a partir de dois critérios: a) que as políticas públicas a ele correspondentes já se encontrassem em um patamar institucional consolidado, ou seja, que fossem representativos do núcleo central dos direitos sociais no Brasil; b) que integrassem expressamente o rol dos direitos sociais estabelecido pelo artigo $6^{\circ}$ da Constituição Federal de 1988.

Seguindo, pois, ambos os critérios, construímos um quadro de análise composto por quatro elementos, além do esporte: educação, saúde, previdência e assistência social. E procedemos ao exame dos dados concernentes a cada um deles, com a finalidade de identificar os pontos de aproximação e distanciamento do direito ao esporte em relação aos demais componentes, tendo por fim último localizar, com base no desenho institucional, qual é a direção predominante do direito ao esporte no país, ou seja, se efetivamente corrobora com os discursos político e acadêmico que o definem como um "direito social" ou, ao contrário, se confirma um dos argumentos de nossa hipótese de trabalho, operando, empiricamente, sob uma perspectiva de acumulação.

Contudo, embora fosse uma operação necessária, a comparação com o desenho institucional de outras políticas sociais nos pareceu insuficiente, por si só, para responder ao nosso problema de pesquisa de modo que acrescentamos outro movimento analítico em nosso estudo. Este consistiu em analisar comparativamente o comportamento das políticas públicas setoriais de esporte em dois governos, sucessivos, mas que possuíam orientações políticas distintas. E elegemos os itens de composição de nosso quadro comparativo apoiando-nos no modelo de análise proposto por Geraldo Di Giovanni (2009). Para este autor, existem alguns elementos das políticas públicas que são invariantes e que se mantêm ao longo do tempo. Ele os denomina estruturas elementares, identificando-as como formal, substantiva, material e simbólica. 
A estrutura formal de uma política pública é composta pelos seguintes elementos: teoria, práticas, objetivos e resultados. Trata-se dos aspectos mais imediatos de uma política, o que inclui: a) a justificativa de sua formulação, que pode ser de natureza técnica, política, cultural ou ideológica; b) as medidas adotadas para a realização de determinados objetivos; e c) os resultados, previstos ou alcançados, a partir da implementação dessas medidas. Partindo de um pressuposto segundo o qual as políticas públicas são um espaço regulamentado de concretização de ações sociais e que, portanto, condensam uma série de interesses provenientes do sentido atribuído pelos indivíduos à participação nesse espaço, o autor define como componentes da estrutura substantiva de uma política pública os seguintes elementos: atores, interesses e regras. Há que se dizer que essas regras não são apenas as previstas na legislação, incluindo também aquelas oriundas das convenções e da cristalização de certas práticas, que interferem na conduta dos atores, individual ou coletivamente considerados. Financiamento, suportes e custos são os elementos invariantes que compõem a estrutura material das políticas públicas, representando os recursos que conferem exequibilidade aos objetivos propostos em seu planejamento. Di Giovanni (2009)afirma que essa tem sido uma dimensão pouco explorada pela literatura acadêmica, o que resulta em significativa limitação para algumas análises, considerando que os aspectos materiais nos permitem encontrar indícios relevantes a respeito das possibilidades de viabilização ou os mecanismos que constrangem o processo de implementação de uma dada política.

Por fim, a estrutura simbólica compreende os valores, saberes e linguagens que se apresentam não apenas na produção dos analistas da política, mas também nas relações que concorrem para a formulação das próprias políticas públicas no interior da arena decisória em que são definidas. Essa última estrutura merece atenção, de acordo com Di Giovanni (2009), na medida em que, a despeito do valor heurístico que as anteriores possuam para a identificação das particularidades de diferentes políticas públicas, é, principalmente, por meio das "linguagens específicas" que se torna possível delinear suas especificidades. Conforme argumenta, essas linguagens

[...] são universos de comunicação próprios (e apropriados) que estabelecem os vínculos entre os diversos tipos de atores de uma dada arena de política. Os elementos da estrutura simbólica são de fato, muito mais que uma expressão cultural neutra dessa atividade social. São também reveladores [...] dos graus de particularismo/universalismo e isolamento/integração das arenas política, bem como dos níveis de racionalização e tecnificação; tradicionalismos e interferências ideológicas que ocorrem nessas mesmas arenas (Di Giovanni, 2009, p.31-32) 
Consideramos que o modelo analítico proposto por este autor permitir-nos-ia elaborar um quadro panorâmico sobre o estado das políticas públicas de esporte durante o período contemplado em nosso recorte de pesquisa e, assim, responder à nossa problemática que, nos moldes em que foi construída, não se refere a uma estrutura elementar específica. Ao contrário, em maior ou menor grau, perpassa o universo das políticas públicas de esporte como um todo. Entendemos que essa abordagem teóricometodológica, como de resto nos parece suceder a qualquer outra, apresenta possibilidades satisfatórias para a leitura sobre nosso objeto de análise, mas também encerra alguns limites. Estamos cientes de que, ao privilegiar um olhar sobre o geral corremos o risco de perder de vista elementos específicos como, por exemplo, a produção e a articulação e/ou disjunção de sentido que se estabelece entre formuladores, implementadores e beneficiários de uma dada política. Contudo, em virtude da problematização aqui proposta, nos parece mais relevante trabalharmos predominantemente no terreno da amplitude do que da profundidade, de sorte que concentramo-nos na primeira, o que nos levou a optar por reconstituir as políticas de esporte no estado do Paraná, ao longo dos governos Lerner e Requião, em suas diferentes estruturas elementares. Orientando-nos por esse modelo analítico, elaboramos um quadro de análise composto pelos elementos a seguir: a) estrutura institucional; b) legislação; c) financiamento; d) programas de governo.

\section{CONSIDERAÇÕES FINAIS}

Este artigo procurou discorrer sobre os elementos teórico-metodológicas que delinearam a estrutura de sustentação de nossa pesquisa de doutoramento, ainda em curso, cujo enfoque é a relação entre as políticas públicas de esporte desenvolvidas ao longo das gestões de Jaime Lerner (1995-2002) e Roberto Requião (2003-2010) e o direito, referido como "social" pelos discursos político e acadêmico, ao esporte. Partindo do plano original de pesquisa, apresentado quando do ingresso no programa de pós-graduação, procuramos recuperar a construção de nosso objeto de estudo, tal como formatado em sua última versão, ressaltando, pois, o caráter dinâmico e processual da pesquisa científica. Nesse sentido, indicamos as premissas que orientavam o projeto em seu início e as modificações que ocorreram à medida que o desenvolvimento acadêmico foi avançando, que culminaram no deslocamento de sua premissa central, de pressuposto da pesquisa, para o centro do problema a ser investigado. 
Essa modificação resultou também em uma alteração na estrutura metodológica da pesquisa, o que está de acordo com a perspectiva de Mannheim (1974) segundo a qual interpelamos os fenômenos sociais armados de conceitos e problemas teóricos, e não a partir de um vazio cultural. Isso nos faz atentar de dois aspectos no processo de construção do conhecimento cuja interdependência não pode ser negligenciada. Trata-se dos pressupostos epistemológicos e do constructo metodológico. Embora sejamos instados, muitas vezes, a expô-los em momentos separados, seja em sua forma escrita ou na exposição oral, é preciso ter clareza de que os primeiros provocam desdobramentos no segundo. Isso significa que, em havendo alterações das premissas que orientam a pesquisa, haverá também implicações de natureza operacional, tal como identificamos no relato de pesquisa aqui documentado.

\section{REFERÊNCIAS BIBLIOGRÁFICAS}

ALMEIDA, B. S. 2010. O financiamento do esporte olímpico e suas relações com a política no Brasil. Curitiba. Dissertação (Mestrado em Educação Física). Universidade Federal do Paraná.

BRACHT, V. 2003. Sociologia crítica do esporte: uma introdução. $2^{a}$ ed. revisada. Ijuí: Unijuí.

BRASIL. 2011. Constituição da República Federativa do Brasil: texto constitucional promulgado em 5 de outubro de 1988, com as alterações adotadas pelas Emendas Constitucionais no 1/92 a 67/2010, pelo Decreto n 186/2008 e pelas Emendas Constitucionais de Revisão nº 1 a 6/94. Brasília: Senado Federal, Subsecretaria de Edições Técnicas.

COHN, G. 1999. Introdução. In: Weber: sociologia. $7^{\mathrm{a}}$ ed. Coordenação: Florestan Fernandes. São Paulo: Ática.

DI GIOVANNI, G. 2009. As estruturas elementares das políticas públicas. Caderno de Pesquisa $n^{\circ}$ 82, Campinas: NEPP/Unicamp, 2009.

DRAIBE, S.M. 1990. As políticas sociais brasileiras: diagnósticos e perspectivas. In: IPEAIPLAN. Para a década de 90: prioridades e perspectivas de políticas públicas. Brasília: IPEA-IPLAN.

ESPING-ANDERSEN, G. 1991. As três economias políticas do Welfare State. Lua Nova, no 24, p.85-116, set.1991.

HALL, P.A.; TAYLOR, R.C.R. 2003. As três versões do neo-institucionalismo. Lua Nova, n.58, p.193-223, 2003.

HARGREAVES, J. 1992. Olympism and nationalism: some preliminary consideration. International Review for the Sociology of Sport, v.27, p.119-135, 1992.

HOBSBAWM, E. 1988. A era dos impérios (1875-1914). $3^{a}$ ed. Tradução: Sieni Maria Campos e Yolanda Steidel de Toledo. Rev. Técnica: Maria Cecília Paoli. Rio de Janeiro: Paz e Terra. 
HOULIHAN, B. 1997. Sport, national identity and public policy. Nations and nationalism, v.3, issue 1, p.113-137, mar.1997.

MANNHEIM, K. 1974. O problema de uma sociologia do conhecimento. In: BERTELLI, A.R.; PALMEIRA, M.G.S., VELHO, O.G. Sociologia do conhecimento. Rio de Janeiro: Zahar.

MARCHI JR, W.; AFONSO, G. 2007. Globalização e esporte: apontamentos introdutórios para um debate. In: RIBEIRO, L.C. (org.). Futebol e globalização. Jundiaí: Fontoura.

MARSHALL, T.H. 1967. Cidadania e classe social. In: Cidadania, classe social e status. Introdução de Phillip C. Schmitter. Trad. Meton Porto Gadelha. Rio de Janeiro: Zahar.

QUIVY, R.; CAMPENHOUDT, L. 1992. Manual de Investigação em ciências sociais. Lisboa: Gradiva.

SANTOS, W.G. 1987. Cidadania e justiça: a politica social na ordem brasileira. $2^{a}$ ed. revista e atualizada. Rio de Janeiro: Campus.

SOUZA, C. 2003. "Estado do campo" da pesquisa em políticas públicas no Brasil. Revista Brasileira de Ciências Sociais, vol.18, nº 51, p.15-20, fev.2003.

STAREPRAVO, F.A. 2011. Políticas públicas de esporte e laz̧er no Brasil: aproximações, intersecções, rupturas e distanciamentos entre os subcampos politico/burocrático e científico/acadêmico. Curitiba. Tese (Doutorado em Educação Física). Universidade Federal do Paraná.

VERONEZ, L.F.C. 2005. Quando o Estado joga a favor do privado: as políticas de esporte após a Constituição Federal de 1988. Campinas. Tese (Doutorado em Educação Física). Universidade Estadual de Campinas.

WEBER, M. 2001a. Metodologia das ciências sociais. Parte 1. 4ª ed. Tradução de Augustin Wernet. Introdução à ed. brasileira: Maurício Tragtenberg. São Paulo: Cortez.

WEBER, M. 2001b. Metodologia das ciências sociais. Parte 2. $3^{\mathrm{a}}$ ed. Tradução de Augustin Wernet. Introdução à ed. brasileira: Maurício Tragtenberg. São Paulo: Cortez. 